\title{
Synthesis and Characterization of Biodegradable Polyurethane for Hypopharyngeal Tissue Engineering
}

\author{
Zhisen Shen, ${ }^{1}$ Dakai Lu, ${ }^{2}$ Qun Li, ${ }^{2}$ Zongyong Zhang, ${ }^{3}$ and Yabin $\mathrm{Zhu}^{2}$ \\ ${ }^{1}$ Lihuili Hospital, Ningbo University, 818 Fenghua Road, Ningbo 315211, China \\ ${ }^{2}$ The Medical School, Ningbo University, 818 Fenghua Road, Ningbo 315211, China \\ ${ }^{3}$ School of Chemical Engineering, Ningbo University of Technology, 201 Fenghua Road, Ningbo 315211, China \\ Correspondence should be addressed to Zhisen Shen; szs7216@163.com and Yabin Zhu; zhuyabin@nbu.edu.cn
}

Received 3 November 2014; Revised 18 January 2015; Accepted 13 February 2015

Academic Editor: Esmaiel Jabbari

Copyright (C) 2015 Zhisen Shen et al. This is an open access article distributed under the Creative Commons Attribution License, which permits unrestricted use, distribution, and reproduction in any medium, provided the original work is properly cited.

\begin{abstract}
Biodegradable crosslinked polyurethane (cPU) was synthesized using polyethylene glycol (PEG), L-lactide (L-LA), and hexamethylene diisocyanate $(\mathrm{HDI})$, with iron acetylacetonate $\left(\mathrm{Fe}(\mathrm{acac})_{3}\right)$ as the catalyst and PEG as the extender. Chemical components of the obtained polymers were characterized by FTIR spectroscopy, ${ }^{1} \mathrm{H}$ NMR spectra, and Gel Permeation Chromatography (GPC). The thermodynamic properties, mechanical behaviors, surface hydrophilicity, degradability, and cytotoxicity were tested via differential scanning calorimetry (DSC), tensile tests, contact angle measurements, and cell culture. The results show that the synthesized cPU possessed good flexibility with quite low glass transition temperature $\left(T_{g},-22^{\circ} \mathrm{C}\right)$ and good wettability. Water uptake measured as high as $229.7 \pm 18.7 \%$. These properties make cPU a good candidate material for engineering soft tissues such as the hypopharynx. In vitro and in vivo tests showed that $\mathrm{CPU}$ has the ability to support the growth of human hypopharyngeal fibroblasts and angiogenesis was observed around cPU after it was implanted subcutaneously in SD rats.
\end{abstract}

\section{Introduction}

Recently, the rate of pharyngeal cancer has been increasing year after year due to alcohol and tobacco abuse [1]. In the literature, $60-80 \%$ of hypopharyngeal head and neck tumor patients were reported to have developed ipsilateral lymph node metastasis upon presentation of clinical symptoms, leading an overall five-year survival rate of $33.4 \%$ $[2,3]$. Surgical removal of the apparent tumor is still an important clinical treatment, although evidence suggests that chemotherapy and radiotherapy can help to control tumor growth and promote patient survival rates [4]. Tumor resection results in tissue defects, which inevitably leads to chronic health problems including hindered breathing, swallowing, vocalizing, and possible mental illness. Clinical surgery is usually performed using jejunal free flap, lateral thigh flap, or pectoralis major myocutaneous flap as the substitutes. However, due to the complex structure of the throat, these substitutes cannot restore pharyngeal function and often result in flap necrosis, infection, fistula, or stenosis
[5-8]. Therefore, it is necessary to find effective and safe substitutes for laryngeal reconstruction.

The rapid development of tissue engineering brings new possibilities for laryngeal and hypopharyngeal reconstruction. Biodegradable materials with good mechanical strength, elasticity, and nontoxicity are good potential candidates as biological substitutes. Poly(lactic acid) (PLA) is a promising material which has been approved by the Food and Drug Administration (FDA) for medical applications. However, there are some drawbacks with the use of PLA as a matrix for hypopharyngeal tissue. For example, it is a stiff polymer with a high glass transition temperature $\left(T_{q}\right)$ of $65^{\circ} \mathrm{C}$, which does not meet the requirements of laryngeal tissue growth.

Polyurethane is a widely used material in tissue engineering because of its good mechanical properties, biocompatibility, and biodegradability $[9,10]$. It is usually synthesized via a crosslinking reaction between diisocyanate and polyhydric hydroxy with polyol or diamine as the extender. Some components such as caprolactone, poly(ethyleneoxide), lactic acid, and ricinoleic acid have been experimented 
TABLE 1: The component feeding ratios and GPC measurements of prepolymer PLEG.

\begin{tabular}{|c|c|c|c|c|}
\hline Copolymer & PEG/L-LA in feeding (mol) & $M_{n}(\mathrm{Da})$ & $M_{w}(\mathrm{Da})$ & $M_{w} / M_{n}$ \\
\hline PLEG 1 & $1.2: 1$ & 4365 & 5926 & 1.3576 \\
\hline PLEG 2 & $1: 1$ & 4702 & 5977 & 1.2709 \\
\hline PLEG 3 & $1: 2$ & 5422 & 6311 & 1.1638 \\
\hline PLEG 4 & $1: 5$ & 6046 & 7312 & 1.2090 \\
\hline
\end{tabular}

with in the production of thermoplastic and biodegradable polyurethanes [11-14]. In our previous work, we studied the catalysis of aliphatic ester polymerization by low toxicity iron compounds, instead of the stannum compounds used commonly in research or/and industry [15]. Using this approach, we synthesized a biocompatible and biodegradable copolymer with $T_{g}$ of $5.6^{\circ} \mathrm{C}$ from monomers of L-lactide, poly(ethylene glycol) (PEG), and NIPAAm [16]. However, the previously published polymer was too rigid to be used in reconstruction of soft tissues like the hypopharynx. In this study, we have produced a material with lower $T_{g}$, better strength, and superior biodegradability using reactions between L-lactide, PEG, and hexamethylene diisocyanate (HDI). The frequency and chemistry of the reaction were characterized by Fourier transform infrared spectroscopy (FTIR), Hydrogen-1 nuclear magnetic resonance ( ${ }^{1} \mathrm{H}$ NMR) spectra, and Gel Permeation Chromatography (GPC). The novel material's mechanical property, hydrophilicity, degradability, cytocompatibility, and in vivo biocompatibility were evaluated. We believe that the material presented in this paper will be a good substitute for hypopharyngeal tissue engineering.

\section{Materials and Methods}

2.1. Materials. PEG (Mn 2000), dichloromethane $\left(\mathrm{CH}_{2} \mathrm{Cl}_{2}\right)$, ethanol, and ethyl acetate were purchased from Sinopharm Chemical Reagent Co., Ltd. L-lactide (L-LA) was supplied by Jinan Daigang Biological Material Company. It was recrystallized three times using ethyl acetate as the solvent prior to reaction. Iron (III) acetylacetonate $\left(\mathrm{Fe}(\mathrm{acac})_{3}\right)$ and $\mathrm{HDI}$ were purchased from Aladdin Reagent Co., Ltd., China.

Trypsin (1:250, GNM) was purchased from Beijing Genosys Scientific Co., China. Mouse anti-vimentin and FITC-conjugated goat anti-mouse IgG were from Wuhan Boster Bio-Engineering Co., Ltd. IRDye 680RD goat antimouse IgG $(\mathrm{H}+\mathrm{L})$ was purchased from LI-COR Biosciences, USA. All cell culture reagents were purchased from HyClone unless otherwise specified. All chemical reagents used for Western blotting were purchased from Beyotime Institute of Biotech, Jiangsu, China. Phosphate buffer saline (PBS, pH7.4) used in cell culture was sterilized prior to use. SpragueDawley (SD) male rats were obtained from the Experimental Animal Center of Ningbo University.

2.2. Synthesis of PLA-PEG-PLA Prepolymer (PLEG). The prepolymer PLEG was synthesized using L-LA and PEG (Mn 2000) as monomers and $\mathrm{Fe}(\mathrm{acac})_{3}$ as the catalyst, as per our previous protocol [12]. Briefly, predetermined amounts of
PEG and L-LA were added into a polymerization tube with $\mathrm{Fe}(\mathrm{acac})_{3}(0.5 \%$, weight ratio to total reactants, resolved in $\mathrm{CH}_{2} \mathrm{Cl}_{2}$ ) as the catalyst. After degassing for $2 \mathrm{~h}$ at $60^{\circ} \mathrm{C}$, the tube was sealed under vacuum and placed entirely into an oil bath and the bath temperature was maintained at $130^{\circ} \mathrm{C}$ for $20 \mathrm{~h}$ with stirring. The polymerization tube was then taken out of the oil bath and cooled to room temperature. Ten milliliters $\mathrm{CH}_{2} \mathrm{Cl}_{2}$ was added to dissolve the product. After precipitation in ethanol at $0^{\circ} \mathrm{C}$, the three-block PLA-PEGPLA prepolymer (PLEG) with different ratios of monomers was obtained (Table 1). The PLEG was subsequently dried in a vacuum oven and kept in the dryer for the next reaction.

2.3. Preparation of Crosslinked Polyurethane. Prepolymer PLEG, PEG, and HDI (molar ratio, $1.65: 10: 2.9$ ) were mixed and heated to $80^{\circ} \mathrm{C}$ for $8 \mathrm{~h}$ under nitrogen protection to allow crosslinking to occur. PLEG and PEG were separately dehydrated via degassing for $1 \mathrm{~h}$ at $110^{\circ} \mathrm{C}$ prior to the crosslinking reaction. A shallow yellow sticky solution was formed at the end of the reaction. It was dissolved in $\mathrm{CH}_{2} \mathrm{Cl}_{2}$ to produce a $50 \%(\mathrm{v}: \mathrm{v})$ solution, which was cast onto a polydimethylsiloxane (PDMS) film and dried in an oven at $60^{\circ} \mathrm{C}$ overnight to yield a flat, approximately $1.0 \mathrm{~mm}$ thick cPU membrane. PDMS was used as the substrate as the synthesized cPU membrane could easily be peeled off.

\subsection{Characterization of Prepolymer and Crosslinked Polymer}

2.4.1. PLEG Prepolymer. FTIR spectra were recorded using an FTIR instrument (Digilab FTS 3100, USA) with $4 \mathrm{~cm}^{-1}$ resolution and a measuring period of $500-4000 \mathrm{~cm}^{-1}$. The reaction chemistry of prepolymer PLEG was confirmed via ${ }^{1} \mathrm{H}$ NMR measurement. PLEG sample was dissolved in $\mathrm{CDCl}_{3}$ and tested on a NMR spectrometer (Bruker Avance, $400 \mathrm{MHz}$, Switzerland). The molecular weight (Mn and Mw) and molecular weight distribution $(\mathrm{Mw} / \mathrm{Mn})$ were determined by GPC (Polymer Laboratories PL-GPC 50 plus, England) using polystyrene as the standard. The analysis was performed at $40^{\circ} \mathrm{C}$ using tetrahydrofuran (THF) as the eluent at a flow rate of $1.0 \mathrm{~mL} / \mathrm{min}$.

2.4.2. Structure and Characteristics of $c P U$. The thermal properties of cPU were tested by differential scanning calorimetry (DSC, Pyris Diamond, USA) under nitrogen. The first heating was from 25 to $100^{\circ} \mathrm{C}$ at a rate of $20^{\circ} \mathrm{C} / \mathrm{min}$ with $1 \mathrm{~min}$ station to clear the thermal history; then the sample was cooled down to $-50^{\circ} \mathrm{C}$ at a rate of $10^{\circ} \mathrm{C} / \mathrm{min}$. The second heating started from $-50^{\circ} \mathrm{C}$ and increased to $100^{\circ} \mathrm{C}$ at a rate of $20^{\circ} \mathrm{C} / \mathrm{min}$. The glass transition temperature $\left(T_{g}\right)$ and melting 
point $\left(T_{m}\right)$ values were taken from the second round of heating.

The static contact angles of cPU were surveyed on a surface tension-contact angle meter (DIGIDROP, GBX, France) and the droplet dynamic contact angle was tested on Dataphysics OCA20 (Germany) at ambient humidity and temperature. A drop of deionized water was approximately 1.0 $\mu \mathrm{L}$ in volume. The contact angle values of samples were averaged from three different locations and expressed as mean \pm standard deviation (SD).

Mechanical properties of $\mathrm{cPU}$ were tested with a tensile tester (Instron 3366, USA) using a linear deformation rate of $10 \mathrm{~mm} / \mathrm{min}$ at $25^{\circ} \mathrm{C}$. Dumbell-shaped polyurethane membranes with a gauge length of $30 \mathrm{~mm}$ and cross-sectional area of $0.2-0.3 \mathrm{~mm} \times 1 \mathrm{~mm}$ were used. Larynx tissue was obtained from Lihuili hospital (Ningbo, China), under agreement of laryngeal carcinoma patients. It was tested and used as references to compare between the synthesized materials and the native tissue. Three repeats were performed for each sample.

Water uptake was tested and calculated as follows: $R(\%)=$ $\left[\left(W_{1}-W_{0}\right) / W_{0}\right] \times 100 \%$, where $W_{0}$ was the original weight and $W_{1}$ was the weight of cPU after being dipped in deionized water for $10 \mathrm{~h}$ at room temperature. Three repeats were performed for $\mathrm{cPU}$.

2.5. Degradation Test. Samples were cut into pieces $40 \times$ $40 \times 1 \mathrm{~mm}$ in size (initial weight $W_{0}$ ) and incubated for $1,5,10,20,40$, or $80 \mathrm{~d}$ in $\mathrm{PBS}(\mathrm{pH}=7.4)$ supplemented with $100 \mathrm{U} / \mathrm{mL}$ penicillin-streptomycin at $37^{\circ} \mathrm{C}$. After rinsing in water and drying in a vacuum oven, samples weights $\left(W_{l}\right)$ were measured on an electronic analytical balance (Sartorius BS 224s, Germany). The percentage of weight loss was calculated using the following formula:

$$
\text { Weight loss }(\%)=\frac{W_{0}-W_{l}}{W_{0}} \times 100 \% \text {. }
$$

$W_{0}$ represents the initial weight of the sample $(\mathrm{mg})$ and $W_{l}$ represents the measured weight $(\mathrm{mg})$ of the same sample after different degradation times. The degradation tests were performed in triplicate for each time point.

\subsection{Primary Human Hypopharyngeal Fibroblast Culture.} Human fibroblasts were obtained from patient hypopharynx connective tissue (sample from Lihuili Hospital in Ningbo, China, under agreement of a pharyngeal carcinoma patient). The tissue sample was rinsed well in sterile PBS containing antibiotics $(1000 \mathrm{U} / \mathrm{mL}$ penicillin and $1000 \mu \mathrm{g} / \mathrm{mL}$ streptomycin sulfate) and sterilized in 75\% ethanol for $5 \mathrm{~s}$ and in 1000 ppm $\mathrm{NaClO}$ solution with PBS washing between steps. After that, the tissue was cut into cubes which were approximately $1 \times 1 \times 1 \mathrm{~mm}$ in dimension and attached to a culture flask (Corning, USA) containing a small amount of culture medium, Dulbecco's Modified Eagle's Medium (DMEM), fetal bovine serum (FBS, 10\%), penicillin (50 IU $/ \mathrm{mL})$, and streptomycin $(50 \mathrm{IU} / \mathrm{mL})$. The culture medium was amended to cover the tissue at the next day. After several days, fibroblasts extended from the tissue cubes and attached to the culture plate. These primary fibroblasts were collected and subcultured for passaging.

The cells with passage $2-4$ were seeded on cPU membrane at the density of $4 \times 10^{4}$ cells $/ \mathrm{mL}$. cPU membrane was cut and prelaid on culture wells (96-well culture plate) with tissue culture polystyrene (TCPS) (Corning, USA) as the positive reference. The culture was incubated in medium consisting of FBS $(10 \%, v / v)$ and DMEM, supplemented with penicillin $(50 \mathrm{IU} / \mathrm{mL})$ and streptomycin $(50 \mathrm{IU} / \mathrm{mL})$ in a humidified air of $5 \% \mathrm{CO}_{2}$ at $37^{\circ} \mathrm{C}$. The culture medium was changed every $2 \mathrm{~d}$. After incubation for some time, cells were fixed with $2.5 \%$ glutaraldehyde for H\&E and immunofluorescent staining.

2.7. Hematoxylin and Eosin (H\&E) Staining. H\&E staining was used to help better visualize the density and morphology of fibroblasts on the cPU membrane due to the opacity of the membrane. The cultures were rinsed three times with PBS and fixed with 4\% paraformaldehyde (Sigma, USA) for 30 minutes at room temperature. The cultures were rinsed thrice with water to remove residual paraformaldehyde and phosphate salts. Subsequently, they were immersed in hematoxylin solution (Beijing Solarbio Science \& Technology, China) for $30 \mathrm{~min}$ to stain cell nuclei, followed by dipping in $1 \%$ hydrochloric acid/alcohol solution for $30 \mathrm{~s}$ to remove the excessive hematoxylin and washing with running water for $5 \mathrm{~min}$. Finally, the samples were immersed in $0.5 \%$ eosin solution (Beijing Solarbio Science \& Technology, China) for $1 \mathrm{~min}$ to stain the cytoplasm. H\&E staining images were taken under light microscopy (Model CX40, Olympus, Japan).

2.8. Immunofluorescent Staining. The fibroblasts seeded on cPU membranes were fixed in $4 \%$ paraformaldehyde for $10 \mathrm{~min}$ at room temperature, washed with PBS thrice for 5 min each time, soaked in $0.2 \%$ Triton X-100 (Beijing Solarbio Science \& Technology, China) for $20 \mathrm{~min}$, and rinsed in PBS thrice for $10 \mathrm{~min}$ each time. After that, the samples were blocked in $10 \%$ goat serum/PBS for $20 \mathrm{~min}$ at $37^{\circ} \mathrm{C}$ followed by incubation in the mouse anti-vimentin primary antibody $\left(1: 200\right.$ dilution in PBS) at $4^{\circ} \mathrm{C}$ overnight. After rinsing with PBS, the samples were incubated in FITCconjugated goat anti-mouse IgG (1:50 dilution in PBS) for $2 \mathrm{~h}$ at $37^{\circ} \mathrm{C}$ in the dark room. Finally, after washing with PBS, the samples were dipped in a 4,6-diamidino-2-phenylindole dihydrochloride (DAPI)/PBS solution (Sigma, $3 \mathrm{mg} / \mathrm{mL}$ ) for $5 \mathrm{~min}$ to stain the nuclei (blue fluorescence). The cells were observed under confocal laser scanning microscopy (CLSM, Olympus Fluoview-1000).

2.9. Mitochondrial Activity Assay. Mitochondrial activity of the cells was measured using the MTT method at days 1, 5,10 , and 14 , respectively. Twenty microliters of $0.5 \mathrm{mg} / \mathrm{mL}$ methylthiazolyldiphenyl-tetrazolium bromide (MTT) solution $(0.5 \mathrm{mg} / \mathrm{mL}$, Beijing Solarbio Science \& Technology, China) was added to each well of the 96 -well plate cultures and incubated at $37^{\circ} \mathrm{C}$ for $4 \mathrm{~h}$ in the dark. $150 \mathrm{~mL}$ dimethylsulphoxide (DMSO) was subsequently added to each culture to dissolve the purple formazan crystal. The absorbance (OD at $490 \mathrm{~nm}$ ) was recorded with an ELISA reader (MaxM5, 
Spectra, USA). The absorbance of the same material in the same solution containing no cells was used as blank reference. Cells cultured on the tissue culture polystyrene (TCPS) were used as the positive reference. Triplicates of each sample were averaged.

2.10. Western Blotting. Cells grown on cPU membrane and TCPS 24-well culture plates for $14 \mathrm{~d}$ were washed three times with PBS for $5 \mathrm{~min}$ each time. Two hundred microliters of radioimmunoprecipitation assay lysis buffer (RIPA) containing phenylmethylsulfonyl fluoride (PMSF) (RIPA : PMSF, $100: 1, v: v)$ (Membrane and Cytosol Protein Extraction Kit, Beijing Solarbio Science \& Technology, China) was added to each well and kept for $30 \mathrm{~min}$ on ice. The cell lysate was collected and centrifuged at $12,000 \mathrm{rpm}$ for $5 \mathrm{~min}$ at $4^{\circ} \mathrm{C}$. The supernatant was collected in a new microcentrifuge tube. Twenty-five microliters of the supernatant was mixed with $5 \mu \mathrm{L}$ XX loading buffer and loaded onto a $12 \%$ sodium dodecyl sulfate (SDS) polyacrylamide gel. Electrophoresis was performed in running buffer at $100 \mathrm{~V}$ for $2 \mathrm{~h}$. The separated proteins were then transferred onto a polyvinylidene fluoride membrane (PVDF, Roche Diagnostics) at $70 \mathrm{~V}$ for $2 \mathrm{~h}$. After blocking with Tris-buffered saline (TBS) containing $5 \%$ skim milk for $1 \mathrm{~h}$ at room temperature, the membrane was incubated in anti-vimentin mouse monoclonal antibody (1:500 dilution in BSA blocking solution) overnight at $4^{\circ} \mathrm{C}$. After three rinses with $0.05 \%$ Tween-20 in TBS (v/v) (TBS$\mathrm{T})$, the PVDF membrane was incubated in goat IR Dye 680 anti-mouse IgG $(\mathrm{H}+\mathrm{L})(1: 15000$ dilution in TBS-T) for $2 \mathrm{~h}$ at $37^{\circ} \mathrm{C}$. The membrane was then scanned and analyzed using the Odyssey infrared scanning imaging system (Odyssey LICOR, USA). The gradation of the target band was calculated with the Odyssey infrared scanning imaging system for statistical analysis. Beta-actin was used to normalize the cellular protein content. The results presented were from three separate experiments.

2.11. In Vivo Biocompatibility. In order to assay the material's in vivo biocompatibility, female SD rats (3 months old, 250-300 g) were anesthetized with 5\% chloral hydrate (intraperitoneal injection, $6 \mathrm{mg} / \mathrm{kg}$ ) and implanted subcutaneously with sterilized cPU discs ( $7 \mathrm{~mm}$ in diameter). After a predetermined period of time, the SD rats were sacrificed and samples were explanted with a small amount of surrounding tissue. These tissue specimens were fixed in $10 \%$ formalin for $1 \mathrm{~h}$, followed by freeze-embedding and microtome slicing into $4 \mu \mathrm{m}$ sections. Samples were stained with H\&E stain and were analyzed under light microscopy (Olympus CX40, Japan). Images were captured by digital camera (PL-B623CU, Pixelink, Canada).

The animals used in this study were treated in accordance with the ethical committee of Ningbo University and the NIH's Principles of Laboratory Animal Care.

\section{Results and Discussion}

3.1. Characterization of PLEG Prepolymer. The PLEG prepolymer was synthesized from the reaction of L-LA and PEG (molecular weight, 2000 Dalton) using a low toxicity iron compound as the catalyst (Scheme 1(a), [16]). The effect of various ratios of L-LA and PEG on the product's molecular weight was explored (Table 1). The molecular weight of PLEG increased with increasing quantities of L-LA. The molecular weight distribution, 1.16-1.35, is very narrow, which showed the low polydispersity of all products due to effective polymerization. The chemistry of PLEG was verified by FTIR spectra (Figure 1), which showed characteristic spectra for PEG (b), L-LA (c), and PLEG 4 (d). Curve (d) (PLEG) appears to be a sum of curve (b) (PEG) and curve (c) (monomeric LLA) with a specific peak at $1756 \mathrm{~cm}^{-1}$, which can be attributed to ester stretching absorption of L-LA and PLEG. The wide peak at $3450 \mathrm{~cm}^{-1}$ can be attributed to hydroxyl groups in the end group of PEG and PLEG (this peak is not present in the L-LA curve). These FTIR characteristics suggest that polymerization occurred between PEG and L-LA to yield the three-block polymer PLEG.

The reaction was also analyzed by ${ }^{1} \mathrm{H}$ NMR using PLEG 4 (mole ratio of PEG: $\mathrm{L}-\mathrm{LA}=1: 5$ ) as the experimental sample (Figure 2). Particularly, both protons of the methyl $\mathrm{CH}_{3}$ at $1.57 \mathrm{ppm}$ (a) and of the $\mathrm{CH}$ with its tertiary carbon attached to hydroxyl and carbonyl groups at $5.17 \mathrm{ppm}$ (c) from the L-LA monomer showed the polylactide (PLA) block, while protons of the $\mathrm{CH}_{2} \mathrm{CH}_{2}$ segment attached to two oxygen atoms at $3.64 \mathrm{ppm}$ (b) were determined to originate from the PEG moiety. The peak area ratio of (a) to (c) was approximately $3: 1$ and confirmed the block structure of $-\mathrm{O}\left(\mathrm{CH}_{3}\right) \mathrm{CHCO}-$ in PLEG. The peak ratio of (b) to $((\mathrm{a})+(\mathrm{c})), 7.1: 4.16$, is close to $2: 1$, demonstrating that the chains of two PLA subblocks were similar; that is, $x \approx y$ in Scheme 1(a). These results indicate that two average blocks of homopolymer PLA and one block of PEG formed the prepolymer PLEG 4 with uniform block weight. This result is considered to be in agreement with the molecular weight measurement of PLEG 4 (6046 Da, Table 1), in which each PEG moiety weighs $2000 \mathrm{Da}$ and each PLA moiety weighs approximately $2000 \mathrm{Da}$.

In order to reduce the crystallinity of the prepolymer and to obtain a crosslinked polyurethane with good flexibility (low $T_{g}$ ), we designed a ring opening reaction between LLA and PEG to produce lower molecular weight prepolymer by using higher amounts of catalyst than those in our previous work [16]. Considering its uniform structure, molecular weight, and polydispersity, PLEG 4 was selected as the reactant for downstream reactions with PEG and HDI.

3.2. Chemistry and Properties of $c P U$. The crosslinking of PLEG 4 and HDI was performed with PEG (Mn 2000) as the extender, to yield the desired cPU (Scheme 1(b)). This crosslinking reaction was confirmed by FTIR spectra (Figure 1), which showed spectra for HDI (a), PEG (b), PLEG (d), and the product $c P U(e)$. Curve (e) (cPU) showed the same peaks as HDI (a), PEG (curve (b)), and PLEG (curve (d)) but without the peak at $2210 \mathrm{~cm}^{-1}$, which is a specific peak of the -NCO-group from HDI, which shows that there is no active -NCO- group in the product. Peaks at 3320 and $1627 \mathrm{~cm}^{-1}$ in cPU were attributed to $\mathrm{C}=\mathrm{O}$ stretching absorption in amide 


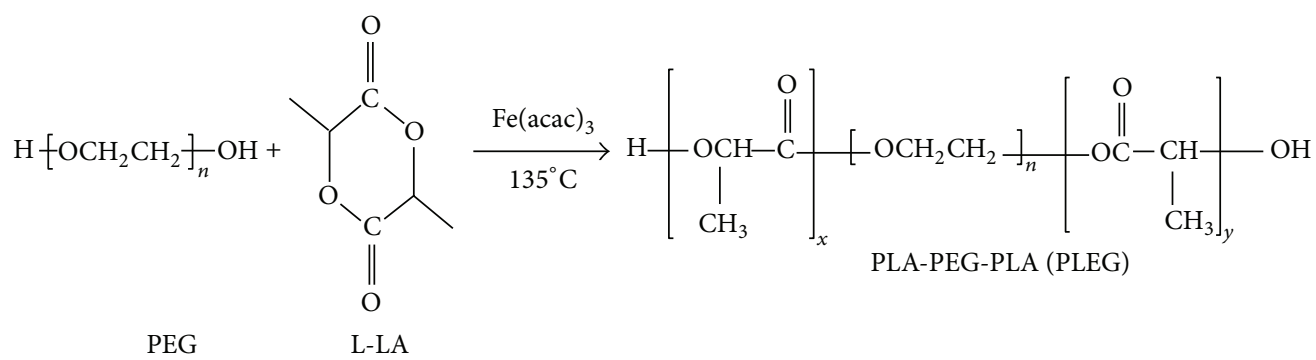

(a)

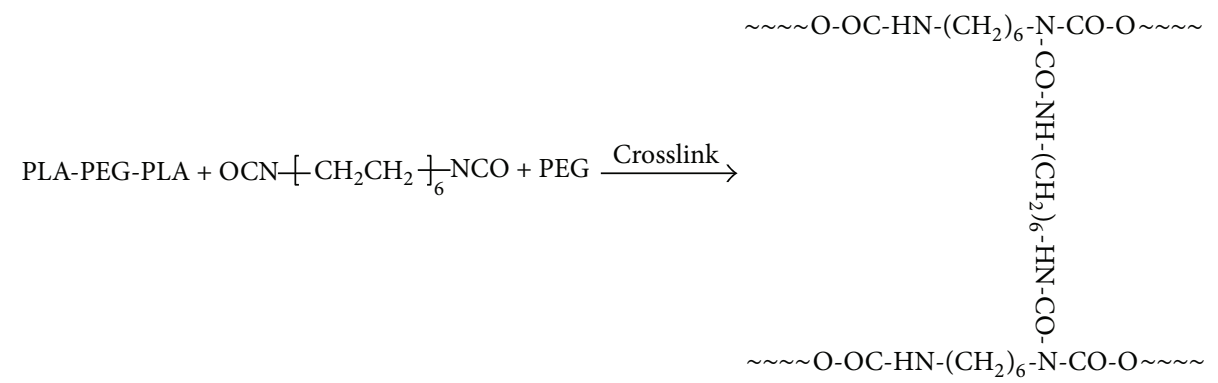

(b)

Scheme 1: Synthesis of oligomer PLA-PEG-PLA (P) using Fe(acac) 3 as the catalyst ((a), cited from [16]) and crosslinking of oligomer PLAPEG-PLA, HDI and PEG (b).

TABLE 2: Properties of cPU film. The cPU was prepared by crosslinking of PLEG4, PEG, and HDI (mole ratio, $1.65: 10: 2.9$ ).

\begin{tabular}{lcccccc}
\hline$T_{g}\left({ }^{\circ} \mathrm{C}\right)$ & $T_{m}\left({ }^{\circ} \mathrm{C}\right)$ & $O ́(\mathrm{MPa})$ & $\varepsilon(\%)$ & $E(\mathrm{MPa})$ & Static contact angle $\left({ }^{\circ}\right)$ & Water uptake $(\%)$ \\
\hline$-22.1 \pm 2.4$ & $61.5 \pm 3.5$ & $4.79 \pm 0.76$ & $72.5 \pm 15.4$ & $31.4 \pm 2.8$ & $71.1 \pm 1.4$ & $229.7 \pm 18.7$ \\
\hline
\end{tabular}

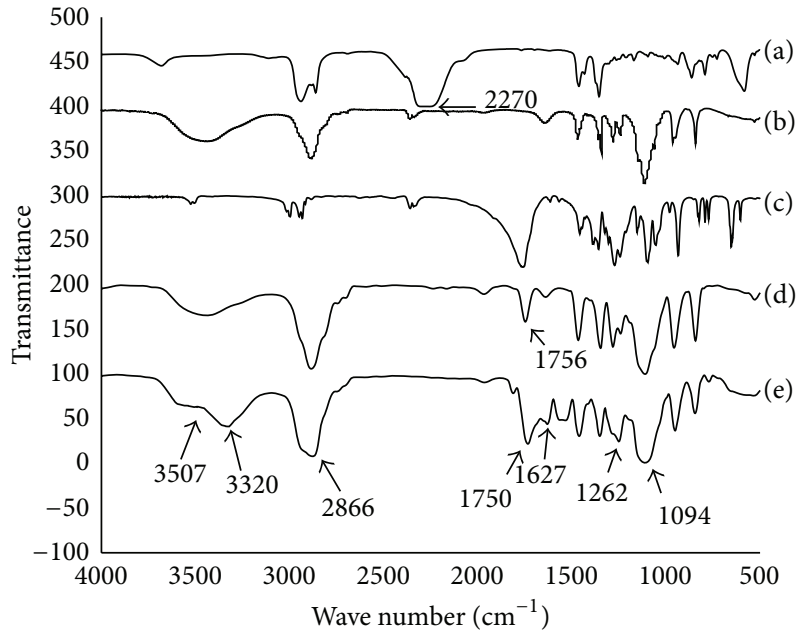

Figure 1: FTIR spectra of HDI (a), PEG (b), L-LA (c), PLEG 4 (d), and $\mathrm{cPU}(\mathrm{e})$. The resolution is $4 \mathrm{~cm}^{-1}$ and the measuring period is $500-4000 \mathrm{~cm}^{-1}$.

groups $\left(\mathrm{O}=\mathrm{C}-\mathrm{NRR}^{\prime}\right)$, while the peak at $3450 \mathrm{~cm}^{-1}(-\mathrm{OH})$ was weakened. A peak at $3507 \mathrm{~cm}^{-1}$, suggesting $\mathrm{N}-\mathrm{H}$ stretching, appeared. Peaks at $1750 \mathrm{~cm}^{-1}$ (ester stretching absorption), $2866 \mathrm{~cm}^{-1}$, and $1094 \mathrm{~cm}^{-1}$ (C-H and ether C-O-C stretching absorption originating from $\mathrm{PEG}$ ) were also observed in the product $\mathrm{cPU}$. Strong absorption from $\mathrm{C}-\mathrm{H}$ stretching

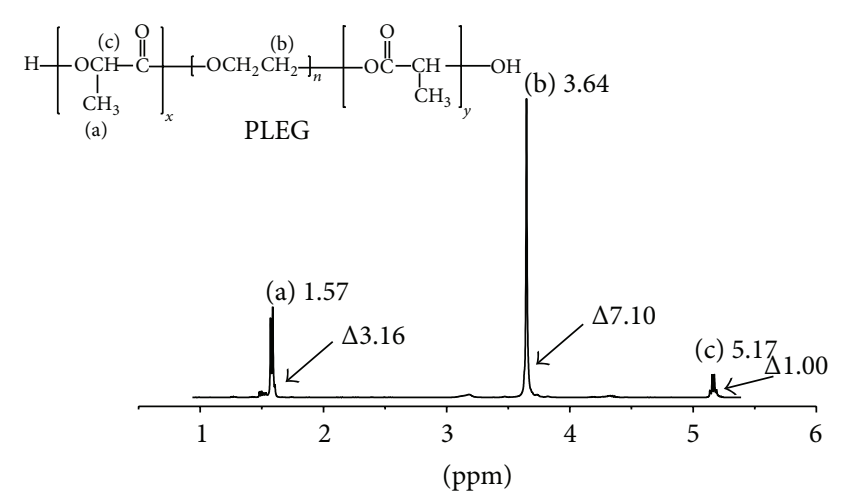

FIGURE 2: ${ }^{1} \mathrm{H}$ NMR spectrum of prepolymer PLEG 4.

suggested a large amount of PEG component. All these results together imply that crosslinking reactions took place between the reactants HDI, PEG, and PLEG.

The thermal and mechanical properties of cPU, as well as its wettability and degradation, were evaluated. The curve in Figure 3(a) shows that the glass transition temperature $\left(T_{g}\right)$ and melting point $\left(T_{m}\right)$ occurred at $-22.1^{\circ} \mathrm{C}$ and $61.5^{\circ} \mathrm{C}$. This quite low $T_{g}$ displayed that $\mathrm{cPU}$ was very flexible at body temperature, $37^{\circ} \mathrm{C}$. These thermal characteristics meet the mechanical requirements for artificial materials to be used as biomatrix for soft tissues. 


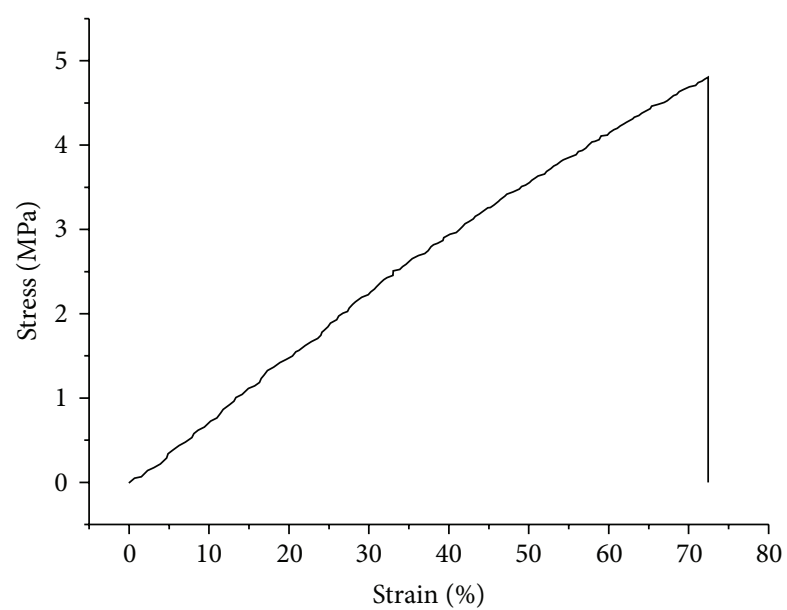

(a)

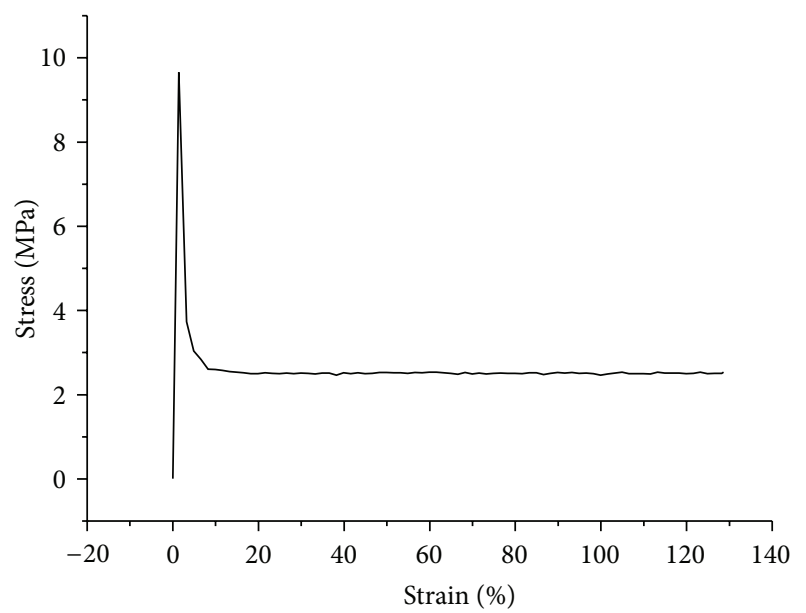

(b)

FIGURE 3: Stress-strain curve of the crosslinked cPU film (a) and larynx tissue (b).

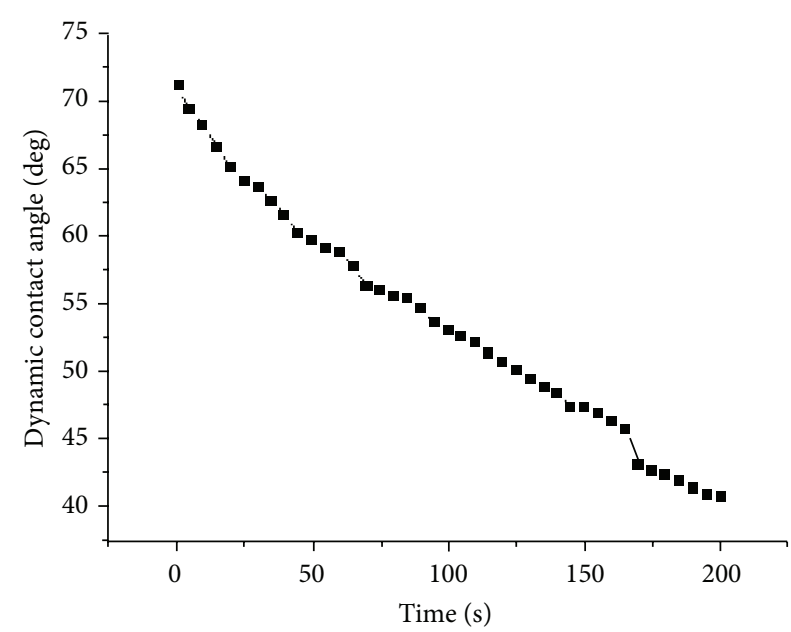

(a)

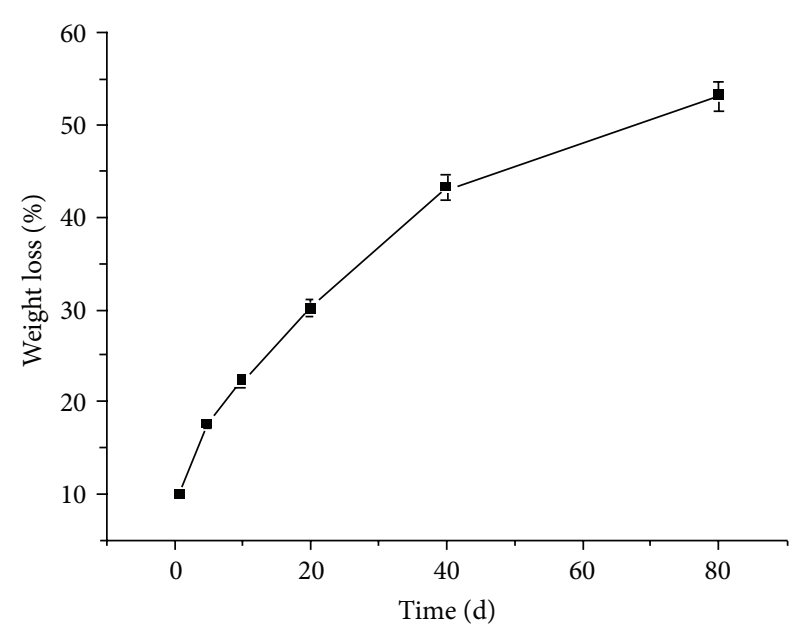

(b)

FIGURE 4: Dynamic contact angle (a) and weight loss (b) of cPU as a function of time. The specimens were immersed in sterilized PBS (pH 7.4) at $37^{\circ} \mathrm{C}$ and kept in a sealed container during weight loss measurement.

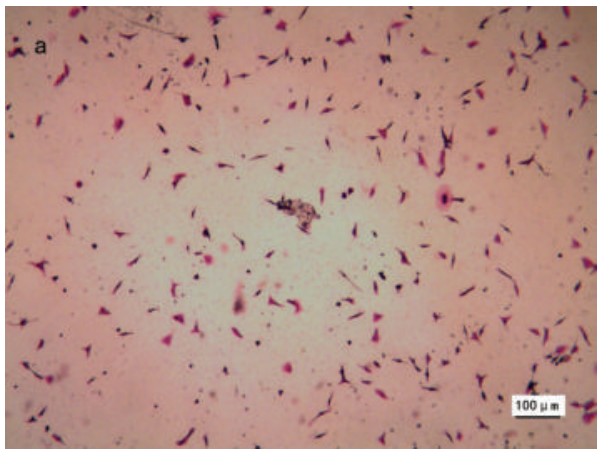

(a)

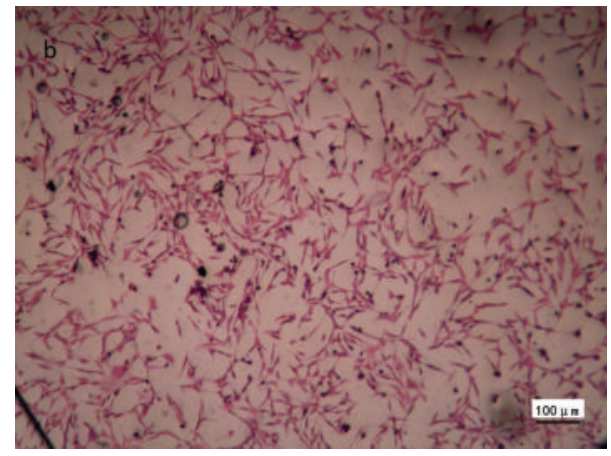

(b)

FIGURE 5: Light microscopy images of cells cultured on cPU membrane for $2 \mathrm{~d}$ (a) and $14 \mathrm{~d}$ (b). Cells were stained by H\&E. The seeding density was $4 \times 10^{4}$ cells $/ \mathrm{mL}$. Scale bar $100 \mu \mathrm{m}$. 

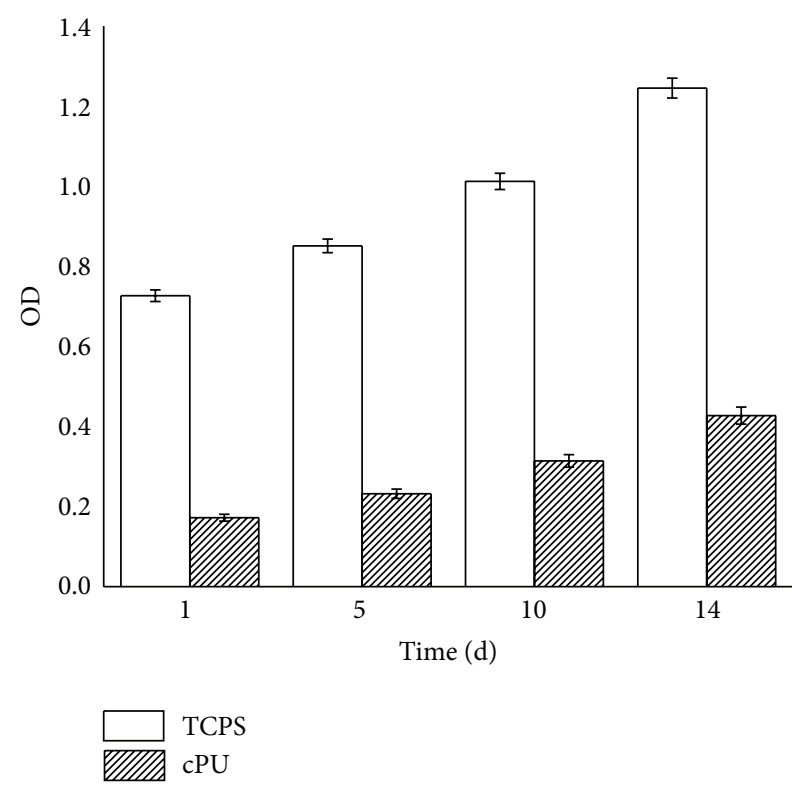

FIGURE 6: Mitochondrial activity as shown by absorbance at $490 \mathrm{~nm}$. Cells were seeded at a density of $4 \times 10^{4}$ cells $/ \mathrm{mL}$ and cultured for 1 day, 5 days, 10 days, and 14 days.

The mechanical properties of cPU are shown as a stress strength-strain curve (Figure 3(a)). The maximum strength and ultimate strain were recorded as $4.79 \pm 0.76 \mathrm{MPa}$ and $72.5 \pm 15.4 \%$. Young's modulus was $31.4 \pm 2.8 \mathrm{MPa}$ (Table 2), which was stronger than natural materials such as collagen (0.31 MPa) [17] or chitosan (0.55 MPa) [18] and biodegradable polymers such as polyvinyl pyrrolidone (0.35 MPa) [19] or aloe vera (1.5 MPa) [20], both of which are often used in biomedical applications. However, it is much weaker than the industry poly(ester urethane) (58213 NAT 022), whose maximum strength and ultimate strain are $17 \mathrm{MPa}$ and $900 \%$, respectively [21]. Moreover, the synthesized cPU in our current study is somewhat brittle, as its ultimate strain is $72.5 \pm 15.4 \%$. After that, the material broke stone-droppedly. In order to know the mechanics of natural tissues, larynx was tested on the same system with the same parameters. Its maximum strength and ultimate strain was $9.65 \pm$ $0.24 \mathrm{MPa}$ and $1.42 \pm 1.31 \%$, respectively. Young's modulus was $692.8 \pm 32.1 \mathrm{MPa}$ (Figure 3(b)). The nature of the larynx seems stronger and more rigid than our synthesized cPU. Hypopharynx was supposed to be softer and more flexible than larynx. However, we are short of the detail data due to shortage of the tissue at present.

An ideal material for tissue engineering should possess good hydrophilicity and biocompatibility. Thus, a hydrophilic PEG component was introduced. PEG is composed of repeating oxyethylene groups, leading to good hydrophilicity and lipophilicity. It is the most common material used to improve hydrophilicity in a scaffold and further promotes the biocompatability and cytocompatibility of the scaffold $[22,23]$. In our case, PEG was introduced as a component of our material. The hydrophilicity of the cPU was evaluated via static and dynamic contact angle measurements. The instant water contact angle was measured as $71.1 \pm 1.4^{\circ}$ (Table 2). This value decreased rapidly with time (Figure 4(a)). After $200 \mathrm{~s}$, the water drop disappeared, presumably absorbed by the material. We also measured the maximum water uptake, $229.7 \pm 18.7 \%$ (Table 2), after dipping the material in water for $10 \mathrm{~h}$, at which point it became a hydrogel with good flexibility and softness, which are good characteristics for hypopharyngeal tissue engineering. An important consideration when designing scaffolds for tissue engineering is degradation, as the rate of degradation of the scaffold should ideally match the growth rate of cells and tissues. For biodegradable polymers, degradation usually takes place in 4 steps: water absorption, reduction of mechanical properties (modulus \& strength), reduction of molar mass, and weight loss due to diffusion of soluble oligomeric components [24, 25]. Therefore, we tested the scaffold's degradation by weight loss measurements. Our measurement of in vitro degradation may help us understand and predict the in vivo behavior of these scaffolds. The in vitro degradation test was performed over a span of $80 \mathrm{~d}$ (Figure 4(b)) and cPU showed rapid degradation kinetics. Weight loss reached 30\% after the first $20 \mathrm{~d}$ and up to $52.5 \%$ by day 80 , which was faster than other materials such as PLLA and PCL [26-28]. It is likely that the good wettability and high water uptake greatly promote the material's degradation.

\subsection{In Vitro Cytocompatibility and In Vivo Biocompatibility.} The cytocompatibility of the synthesized cPU was firstly measured via human hypopharyngeal fibroblast seeding. Cell morphology, activity, phenotype, and protein expression were tested. Due to its hydrophilicity, cPU swelled significantly in the cell culture medium and in the body during the in vivo test. As a result, scanning electron microscopy (SEM) was not used for the observation of cell morphology. Under light microscopy, cells were visible after primary fibroblasts were cultured on the cPU membrane for $2 \mathrm{~d}$ (Figure 5(a)). There were many more live cells on the membrane at day 14 (Figure 5(b)). Cells were stained by $\mathrm{H} \& \mathrm{E}$ in order to visualize them on the membrane. MTT test showed that the seeded cells grew and proliferated with time, although the mitochondrial activity (as determined by OD value) was lower than that on TCPS at every time point during the $14 \mathrm{~d}$ culture span (Figure 6). Mitochondrial activity on cPU at day 14 only reached $36 \%$ of that on TCPS. This value was similar to the activity of skeletal muscle cell from human hypopharynx on poly(ester urethane) (58213 NAT 022, China) [21]. The much higher hydrophicility of cPU resulted in the lowered cell adhesion (OD at day 1). However, the increase rate of OD value from day 1 to day 14 is quite similar between $\mathrm{CPU}$ and TCPS, which means the similar cell proliferation capability between these two matrices. On the other hand, cPU was found to possess rapid degradation rate from weight loss test (Figure 4(b)). It may make fibroblasts very difficult to adhere firmly on the matrix with the passing time, leading to lower test results than the reality is. Despite this, the cells cultured on cPU had a fibroblast-like phenotype. Vimentin is the intermediate filament in fibroblasts. Thus, it is a reliable fibroblast marker. Using anti-vimentin as the primary antibody, cells 

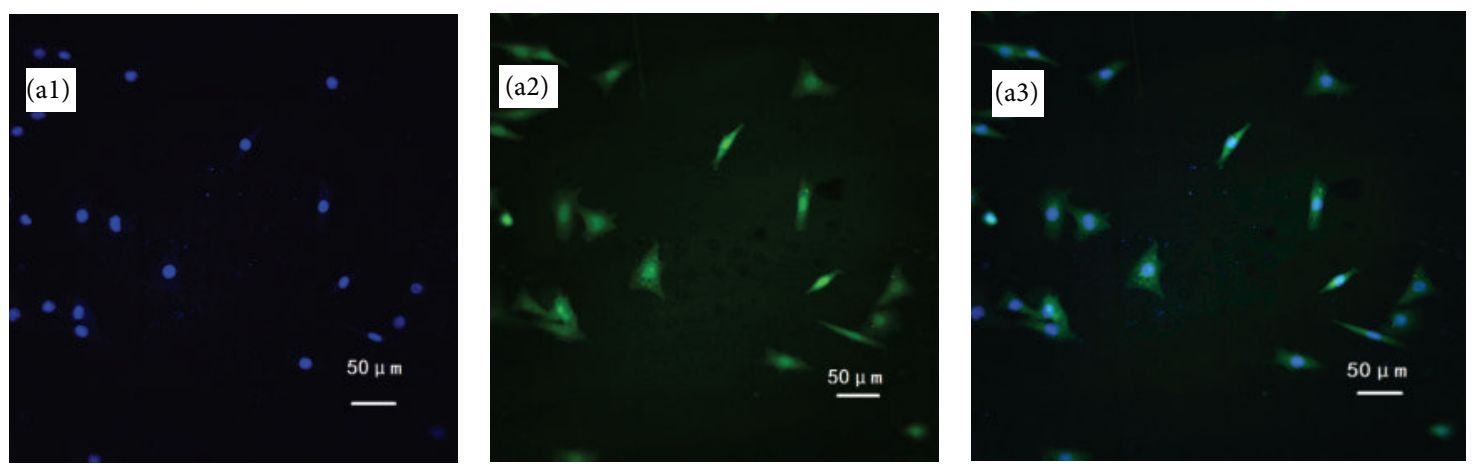

(a)
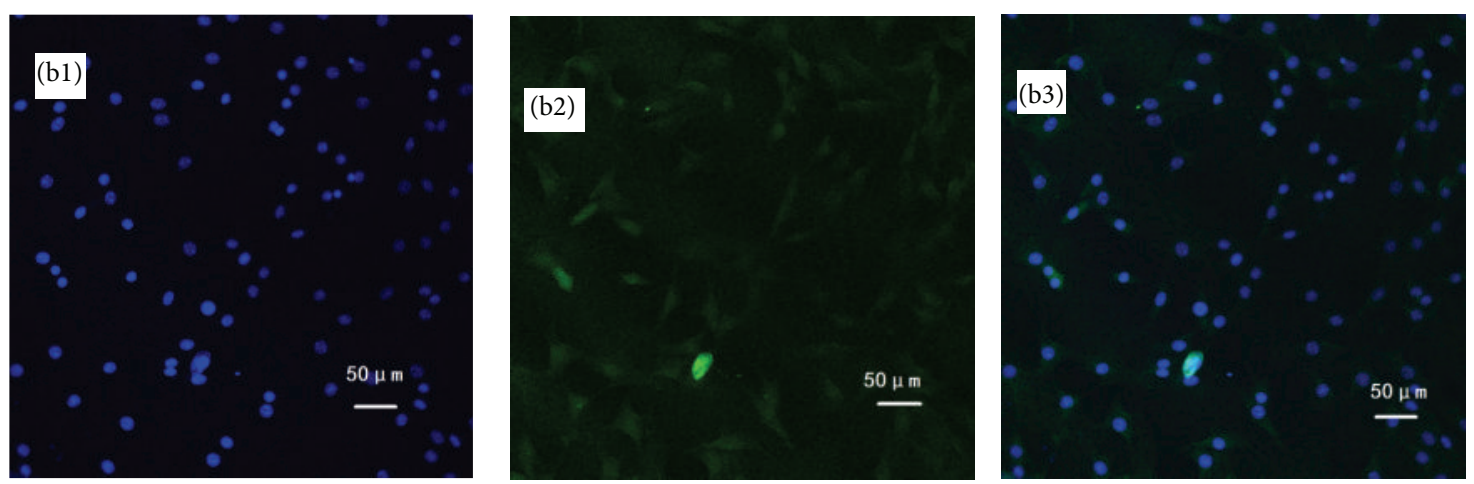

(b)

FIGURE 7: Immunofluorescence of cells cultured on cPU membrane for $2 \mathrm{~d}$ (a) and $14 \mathrm{~d}$ (b). Anti-vimentin was used as the primary antibody and appears in the cytoplasm as green fluorescence. The nucleus is blue from DAPI staining. The seeding density was $4 \times 10^{4}$ cells $/ \mathrm{mL}$. Image (3) is an overlay of images (1) and (2). Scale bar $50 \mu \mathrm{m}$.

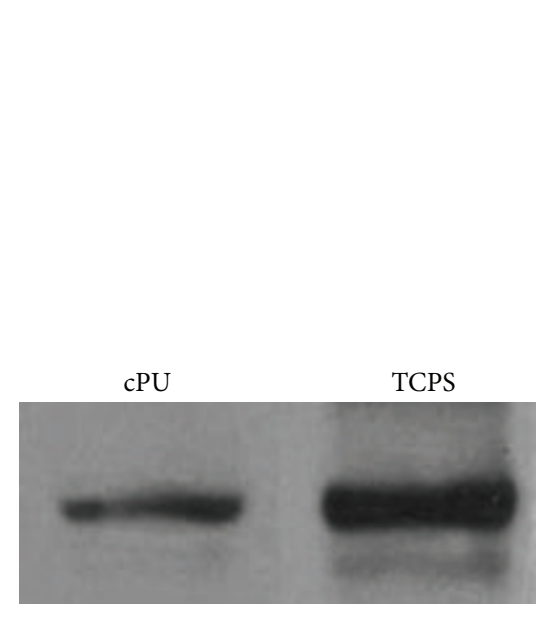

(a)

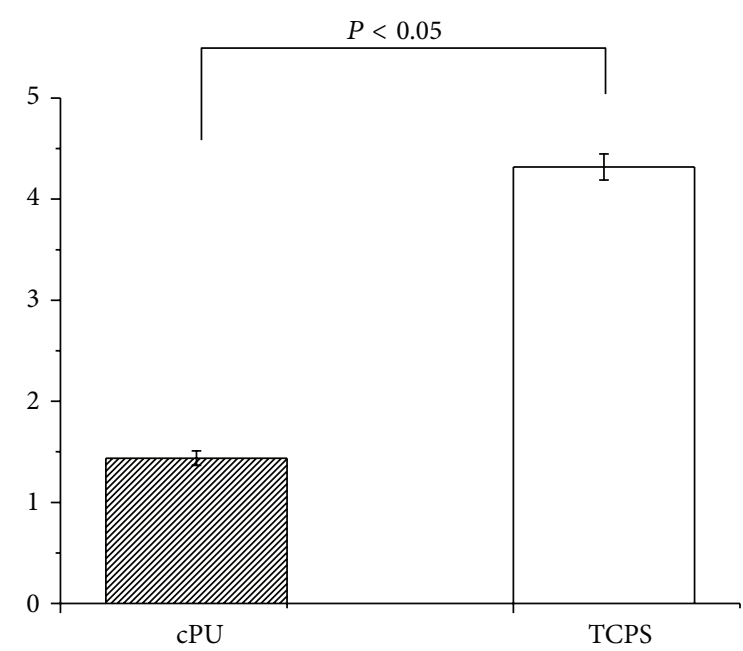

(b)

FIGURE 8: Vimentin expression by cells seeded on cPU and TCPS for $14 \mathrm{~d}$, analyzed by Western blotting. (a) Strips of cPU and TCPS. (b) Quantitative analysis of vimentin expression. Beta-actin was used as the reference to normalize the cellular protein content. $P$ value is $<0.05$.

on cPU substrates were immuno-stained (green fluorescence) to confirm the fibroblasts after they had been cultured in vitro from $2 \mathrm{~d}$ to $14 \mathrm{~d}$ (Figure 7). Quantification of vimentin expression verified that the cultured cells still had the ability to differentiate (Figure 8). The amount of vimentin secreted by cells grown on CPU was $35 \%$ of that of cells on TCPS at day
14, which was in agreement with the result of mitochondrial activity analysis.

In order to ascertain the in vivo biocompatibility of our synthetic material, cPU was implanted subcutaneously into the back of SD rats. After implantation for 7, 21, 49, and $70 \mathrm{~d}, \mathrm{SD}$ rats were anaesthetized and the location of the $\mathrm{CPU}$ 

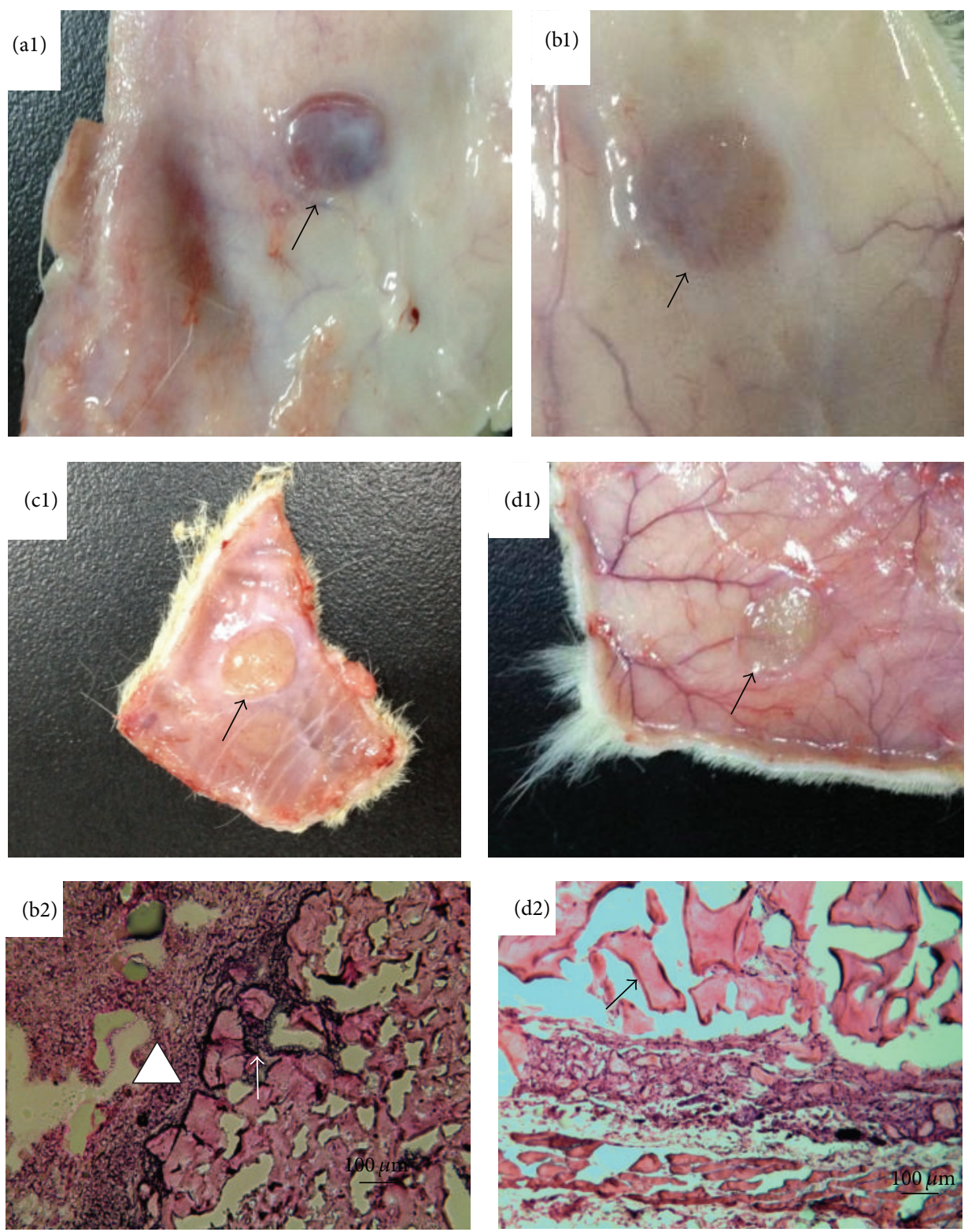

FIGURE 9: Appearance of subcutaneously implanted cPU membrane in the back of SD rats for $7 \mathrm{~d}(\mathrm{al}), 21 \mathrm{~d}(\mathrm{bl}), 49 \mathrm{~d}(\mathrm{cl})$, and $70 \mathrm{~d}(\mathrm{dl})$ ); arrow indicates the location of the material. (b2) H\&E staining of microtome section after $21 \mathrm{~d}$ implantation; white triangle and arrow indicate the site filled with inflammatory cells. (d2) H\&E staining of microtome section after $70 \mathrm{~d}$ implantation. Arrow indicates the biodegraded fragment. Scale bar $100 \mu \mathrm{m}$.

membrane was exposed. By visual observation, the subcutaneous samples were already enclosed in the skin hypodermis after $7 \mathrm{~d}$. However, a small amount of inflammation and serious blood swelling were observed all around the membrane (Figure 9(a1), arrow). By day 49, the blood swelling was comparatively reduced (Figure 9(b1), arrow). However, many inflammatory cells filled the circumference of the material (Figure 9(b2), white triangle), while some inflammatory cells had infiltrated into the material interspace (Figure 9(b2), white arrow). The inflammation and blood swelling reduced significantly by day 49 (Figure $9(\mathrm{cl})$, arrow) and were completely resolved by day 70 (Figure 9 (d1), arrow). Angiogenesis was observed around the sample, which greatly promotes the biocompatibility of the scaffold. H\&E staining revealed the clear tissue structure (Figure 9(d2)). However, during this period of time, the material had begun to biodegrade and some fragments could be observed (Figure 9(d2), arrow). We considered the material to have been accepted by the animal body.

\section{Conclusions}

A biodegradable polyurethane $\mathrm{cPU}$ was produced by crosslinking HDI, PEG, and prepolymer PLEG, which was synthesized from the reaction between L-LA and PEG using $\mathrm{Fe}(\mathrm{acac})_{3}$ as the catalyst. The reaction chemistry was 
followed and analyzed via FTIR spectroscopy, ${ }^{1} \mathrm{H}$ NMR, and GPC. The synthesized cPU possesses low $T_{g}\left(-22^{\circ} \mathrm{C}\right)$, good hydrophilicity, and relatively fast degradation. It also has the ability to support the growth of human hypopharyngeal fibroblasts. Subcutaneous implantation in SD rats suggests that the material has good biocompatibility. However, the material is still weak and degrades rather quickly when compared with industrial polyurethane products. The synthesis reaction and product chemistry are being improved in our laboratory in order to meet the requirements of a good scaffolding material for hypopharyngeal tissue engineering.

\section{Conflict of Interests}

The authors declare that there is no conflict of interests regarding the publication of this paper.

\section{Acknowledgments}

Financial support from Major Project Foundation of Ningbo (2012C5015), Scientific Innovation Team Project of Ningbo (2012B82019), and National Science Foundation (81171476 and 81471797 ) of China are gratefully acknowledged. This work was also sponsored by the K.C. Wang Magna Fund of Ningbo University.

\section{References}

[1] A. Fortin, C. S. Wang, and É. Vigneault, "Influence of smoking and alcohol drinking behaviors on treatment outcomes of patients with squamous cell carcinomas of the head and neck," International Journal of Radiation Oncology Biology Physics, vol. 74, no. 4, pp. 1062-1069, 2009.

[2] C. G. Gourin and D. J. Terris, "Carcinoma of the hypopharynx," Surgical Oncology Clinics of North America, vol. 13, no. 1, pp. 8198, 2004.

[3] J. Y. W. Chan and W. I. Wei, "Current management strategy of hypopharyngeal carcinoma," Auris Nasus Larynx, vol. 40, no. 1, pp. 2-6, 2013.

[4] J. Bourhis, J. Overgaard, H. Audry et al., "Hyperfractionated or accelerated radiotherapy in head and neck cancer: a metaanalysis," The Lancet, vol. 368, no. 9538, pp. 843-854, 2006.

[5] D. Perez-Smith, M. Wagels, and D. R. Theile, "Jejunal free flap reconstruction of the pharyngolaryngectomy defect: 368 consecutive cases," Journal of Plastic, Reconstructive \& Aesthetic Surgery, vol. 66, no. 1, pp. 9-15, 2013.

[6] E. M. Genden and A. S. Jacobson, "The role of the anterolateral thigh flap for pharyngoesophageal reconstruction," Archives of Otolaryngology: Head and Neck Surgery, vol. 131, no. 9, pp. 796799, 2005.

[7] R. Liu, P. Gullane, D. Brown, and J. Irish, "Pectoralis major myocutaneous pedicled flap in head and neck reconstruction: retrospective review of indications and results in 244 consecutive cases at the Toronto General Hospital," Journal of Otolaryngology, vol. 30, no. 1, pp. 34-40, 2001.

[8] R. S. Patel, D. P. Goldstein, D. Brown, J. Irish, P. J. Gullane, and R. W. Gilbert, "Circumferential pharyngeal reconstruction: history, critical analysis of techniques, and current therapeutic recommendations," Head and Neck, vol. 32, no. 1, pp. 109-120, 2010.
[9] X. Jiang, J. Gu, L. Lin, and Y. Zhang, "Investigation on the modification to polyurethane by multi-walled carbon nanotubes," Pigment \& Resin Technology, vol. 40, no. 4, pp. 240-246, 2011.

[10] T. Yoshii, A. E. Hafeman, J. M. Esparza, A. Okawa, G. Gutierrez, and S. A. Guelcher, "Local injection of lovastatin in biodegradable polyurethane scaffolds enhances bone regeneration in a critical-sized segmental defect in rat femora," Journal of Tissue Engineering and Regenerative Medicine, vol. 8, no. 8, pp. 589595, 2014.

[11] A. S. More, T. Lebarbé, L. Maisonneuve, B. Gadenne, C. Alfos, and H. Cramail, "Novel fatty acid based di-isocyanates towards the synthesis of thermoplastic polyurethanes," European Polymer Journal, vol. 49, no. 4, pp. 823-833, 2013.

[12] X. Pan, P. Sengupta, and D. C. Webster, "High biobased content epoxy-anhydride thermosets from epoxidized sucrose esters of fatty acids," Biomacromolecules, vol. 12, no. 6, pp. 2416-2428, 2011.

[13] R. Slivniak and A. J. Domb, "Lactic acid and ricinoleic acid based copolyesters," Macromolecules, vol. 38, no. 13, pp. 55455553, 2005.

[14] S. A. Guelcher, "Biodegradable polyurethanes: synthesis and applications in regenerative medicine," Tissue Engineering, Part B: Reviews, vol. 14, no. 1, pp. 3-17, 2008.

[15] Y. N. Lei, Y. B. Zhu, L. Chen, and L. X. Hou, "Polymerization of aliphatic cyclic ester using ironcompounds as catalysts," Chinese Journal of Polymer Science, vol. 24, pp. 297-302, 2011.

[16] Y. N. Lei, Y. B. Zhu, C. F. Gong, J. J. Lv, C. Kang, and L. X. Hou, "Synthesis, characterization and cytocompatibility of a novel degradable polymer using iron compound as catalyst," Journal of Materials Science: Materials in Medicine, vol. 2, pp. 273-282, 2014.

[17] A. M. Haaparanta, E. Järvinen, I. F. Cengiz et al., "Preparation and characterization of collagen/PLA, chitosan/PLA, and collagen/chitosan/PLA hybrid scaffolds for cartilage tissue engineering," Journal of Materials Science: Materials in Medicine, vol. 25, no. 4, pp. 1129-1136, 2014.

[18] X. Zhong, C. Ji, A. K. L. Chan, S. G. Kazarian, A. Ruys, and F. Dehghani, "Fabrication of chitosan/poly( $\varepsilon$-caprolactone) composite hydrogels for tissue engineering applications," Journal of Materials Science: Materials in Medicine, vol. 22, no. 2, pp. 279$288,2011$.

[19] G.-M. Kim, K. H. T. Le, S. M. Giannitelli, Y. J. Lee, A. Rainer, and M. Trombetta, "Electrospinning of PCL/PVP blends for tissue engineering scaffolds," Journal of Materials Science: Materials in Medicine, vol. 24, no. 6, pp. 1425-1442, 2013.

[20] P. Jithendra, A. M. Rajam, T. Kalaivani, A. B. Mandal, and C. Rose, "Preparation and characterization of aloe vera blended Collagen-Chitosan composite scaffold for tissue engineering applications," ACS Applied Materials \& Interfaces, vol. 5, no. 15, pp. 7291-7298, 2013.

[21] Z. Shen, S. Guo, D. Ye et al., "Skeletal muscle regeneration on protein-grafted and microchannel-patterned scaffold for hypopharyngeal tissue engineering," BioMed Research International, vol. 2013, Article ID 146953, 8 pages, 2013.

[22] A. K. Gaharwar, C. Rivera, C.-J. Wu, B. K. Chan, and G. Schmidt, "Photocrosslinked nanocomposite hydrogels from PEG and silica nanospheres: structural, mechanical and cell adhesion characteristics," Materials Science and Engineering C: Materials for Biological Applications, vol. 33, no. 3, pp. 1800-1807, 2013.

[23] A. W. Smith, J. D. Hoyne, P. K. Nguyen et al., "Direct reprogramming of mouse fibroblasts to cardiomyocyte-like cells using 
Yamanaka factors on engineered poly(ethylene glycol) (PEG) hydrogels," Biomaterials, vol. 34, no. 28, pp. 6559-6571, 2013.

[24] M. Hakkarainen, A. C. Albertsson, and S. Karlsson, "Weight losses and molecular weight changes correlated with the evolution of hydroxyacids in simulated in vivo degradation of homoand copolymers of PLA and PGA," Polymer Degradation and Stability, vol. 52, no. 3, pp. 283-291, 1996.

[25] A. Göpferich, "Mechanisms of polymer degradation and erosion," Biomaterials, vol. 17, no. 2, pp. 103-114, 1996.

[26] A. Höglund, M. Hakkarainen, and A.-C. Albertsson, "Migration and hydrolysis of hydrophobic polylactide plasticizer," Biomacromolecules, vol. 11, no. 1, pp. 277-283, 2010.

[27] J. E. Bergsma, W. C. de Bruijn, F. R. Rozema, R. R. M. Bos, and G. Boering, "Late degradation tissue response to poly(L-lactide) bone plates and screws," Biomaterials, vol. 16, no. 1, pp. 25-31, 1995.

[28] P. Shokrollahi, M. Mehmanchi, M. Atai, H. Omidian, and F. Shokrolahi, "Effect of interface on mechanical properties and biodegradation of PCL HAp supramolecular nano-composites," Journal of Materials Science: Materials in Medicine, vol. 25, no. 1, pp. 23-35, 2014. 


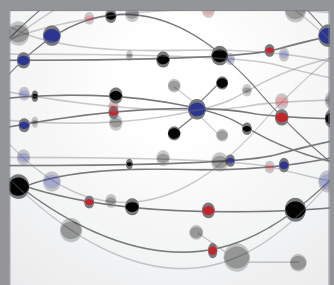

The Scientific World Journal
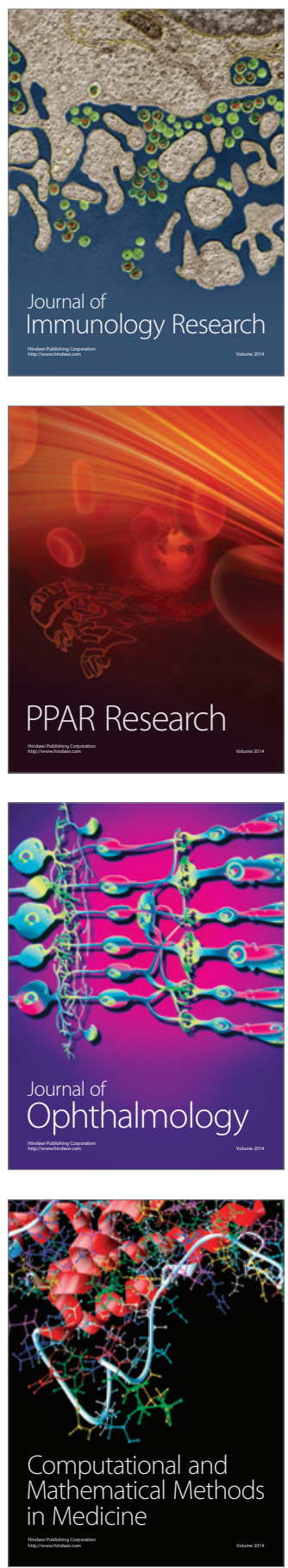

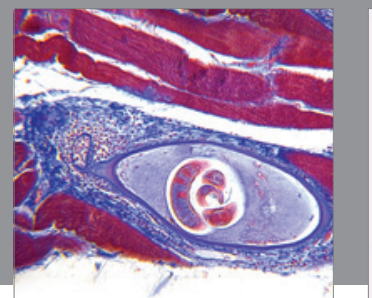

Gastroenterology

Research and Practice
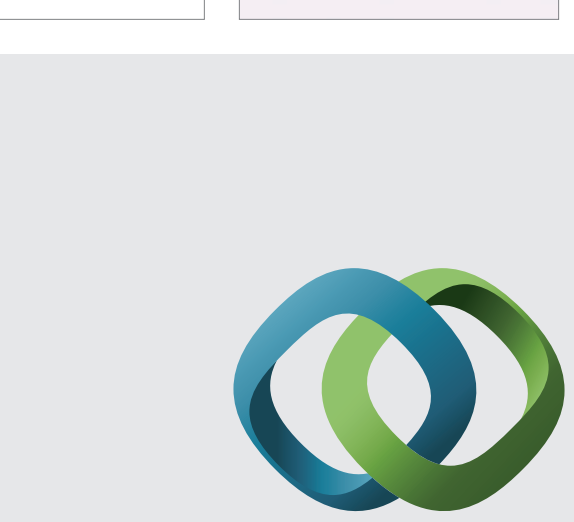

\section{Hindawi}

Submit your manuscripts at

http://www.hindawi.com
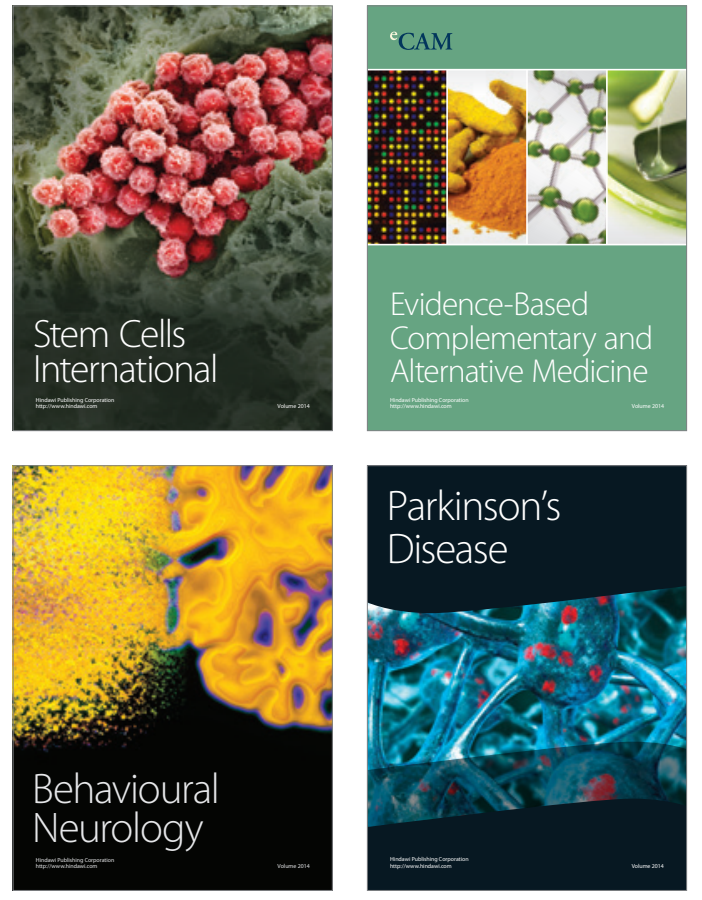
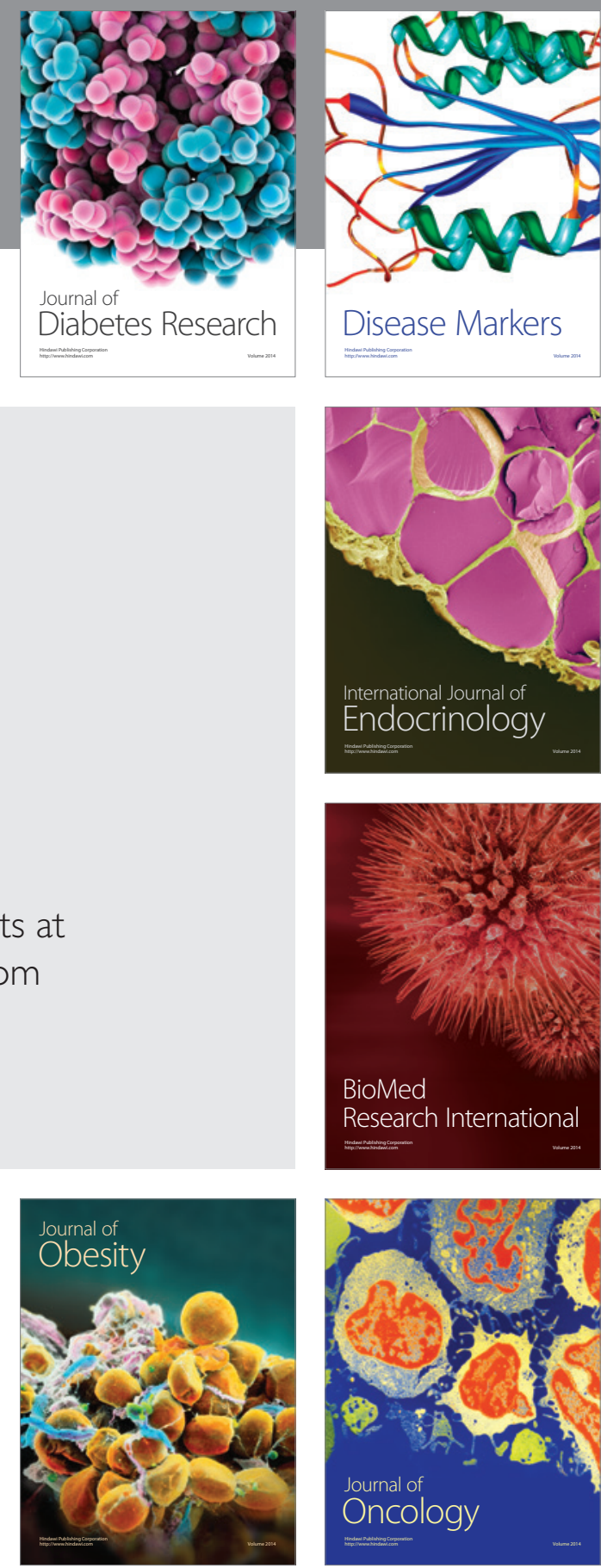

Disease Markers
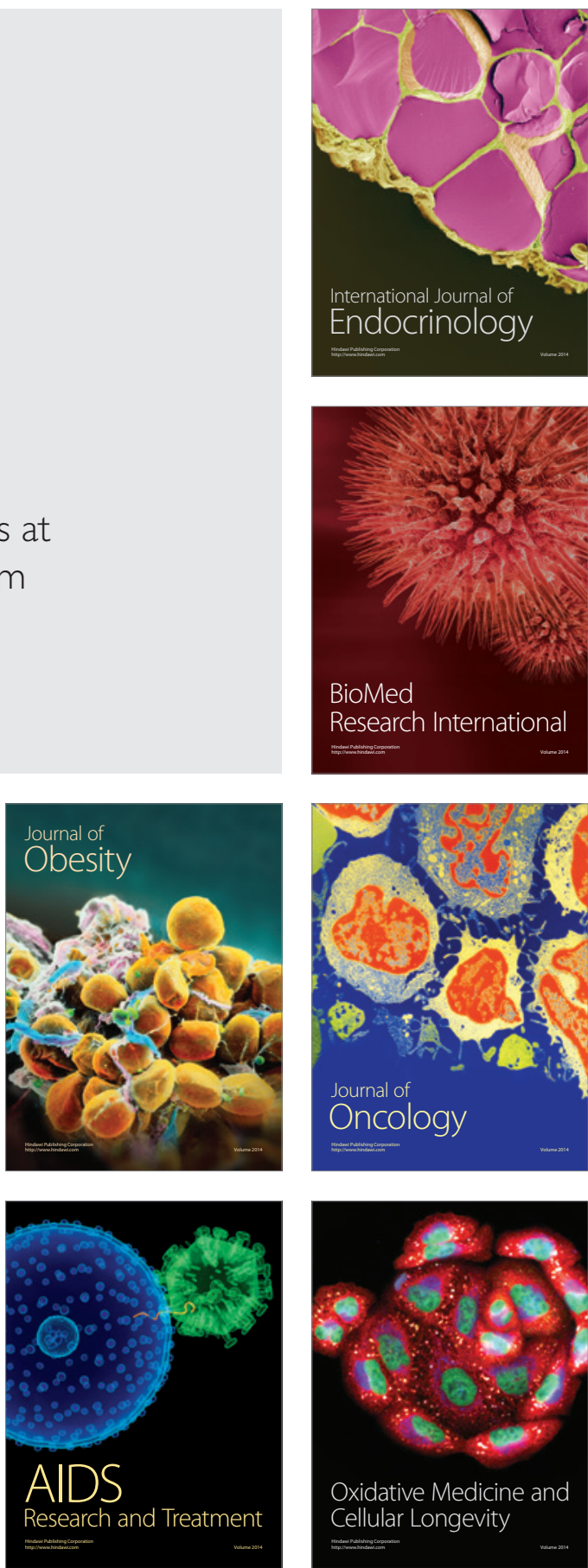